\title{
MODELING OF TIME DELAYED PROCESSES IN BUSINESS ECONOMICS
}

\author{
Martina BOBALOVÁa*, Veronika NOVOTNÁ ${ }^{b}$ \\ ${ }^{a, b}$ Brno University of Technology, Czech Republic
}

\begin{abstract}
The growth of mutual dependence and interconnection of markets of both national economies and multinational groups in the form of globalization processes is a typical characteristic of the current economic development. The turbulent environment of rapidly developing markets creates conditions for an increase in competition among econlomic entities, which is one of the main reasons for better allocation of factors of production and more efficient manufacturing, leading to improved competitiveness in the global market.

In business practice, there are a number of phenomena characterized by changes and dynamics. Understanding the dynamics of these changes is crurial for the management decision-making since consumer behaviour changes in time these days. Therefore, we may perceive a company in a given context as a dynamic system with multiple elements and connections. In the business environment, we may consider production, consumption, investments and others to be static variables. A model of such a dynamic system is usually based on a system of differential equations describing changes of the static vector in time. This type of equations has been increasingly used in modelling of changes and motion in various scientific fields.
\end{abstract}

KEYWORDS: economic dynamic model; decision-making in business management; differential equations with delay; modelling

DOI: 10.24818/IMC/2021/01.08

\section{INTRODUCTION}

The word dynamic is of Greek origin, where dynamis means force. These days we understand the word dynamic in terms of Newton's law (see Newton, 1687) that says that if a force is acting on an object, the object moves with an acceleration directly proportional to the acting force and inversely proportional to the weight of the object. In other words, a non-zero resultant force causes a non-zero acceleration.

A dynamic system (see e.g. (Kindler, 1980, Křivý \& Kindler, 2001, Nemyckii, 1962)) is a system whose status can be described at any given moment in time by a finite set of static variables, constants and equations. The status of a dynamic system at a given moment in time completely determines its development (i.e. determines the values the static variables may acquire in time). Simulations of dynamic system behaviour through corresponding dynamic models are used effectively to investigate the behaviour of such systems, in particular for predictions in various conditions. It is naturally assumed that the created dynamic model is realizable and that the values of its static variables at time $t$ can only be affected by factors acting before moment $t$. Therefore, time enters the dynamic model as an internal variable of the investigated dependence.

The changes in the static quantity values and the corresponding models may be described as discrete models (changes of values $X(t)$ to values $X(t+\Delta t)$ are random quantities whose basic characteristics are known), as continuous models (changes of values $\mathrm{X}(\mathrm{t})$ to values $X(t+\Delta t)$ are expressed by a

${ }^{*}$ Corresponding author. E-mail address: bobalova@fbm.vutbr.cz 
continuous function that is known), and as mixed models (part of the static quantities is affected by random changes and part is changed continuously). Based on the character of the considered connections, we differentiate between deterministic and stochastic simulations.

A dynamic model describes system behaviour in terms of one quantitative status changing into another. The term dynamic denotes changes that are expressed in time, and from this perspective, time is an important factor. In short, a dynamic model is every model in which its variables are represented with a time index and in which there is a relation between current and past variables. Dynamic linear models are the best known representative of dynamic models.

\section{MANUSCRIPT}

\subsection{Dynamic models in economics and business management}

The main function of business management is achieving the best possible results based on its strategies and their stabilization, and therefore it is important that the company management proceeds in line with the dynamics of the changing market behaviour, is capable of fast adaptation, increased flexibility, meeting market demands and optimizing results. The dynamics of current consumer behaviour and the resulting changes in needs require modifications of approach on the part of the manufacturers and their management systems, and business economics thus becomes a priority of economic sciences.

For this reason, it is very important that the company management understands the real consumer needs and projects these needs in the products or services that are increasingly connected to consumer behaviour and its changes, keeps improving production processes and increases efficiency at the same time. To this end, the option of simulating the intended process of change by a dynamic model is used very often. Most often, these models are used for production processes, marketing, information and cash flows. The time delay usually represents various effects of the modelled problem, such as transmission, transport and inertial effects.

In the past, business management mostly dealt with models of optimization of factors of production, investment programmes, funding and storing. The solutions gradually used linear and non-linear planning models, graph theory, combinatorics, decision tree methods as well as game theory findings. In the mid-20th century, there was a substantial development in science and technology, including the application of mathematics in business management. References can be found for example in (Andreeva et al., 1992; Titov \& Uspenskii, 2013). More and more often, new mathematical models appear, describing the dynamic model by differential equations, which can be used for real description of various processes from practical life.

In the 1960s, professor Forrester laid the basis of the so-called system dynamics and thanks to information technology development, system dynamics contributed to the creation of dynamic models of business processes. Gradually, very extensive models emerged, such as the Beer Game manager game, models of economic cycles and others.

System oriented business management strives to formulate creative models for future realities. Business management is then perceived as a cybernetic science, which is not interested in exsitence but in system functioning. (Synek et al., 2013).

When creating a model of organization management, authors of the book (McGarvey \& Hannon, 2004) recommend to use a strategy that can be summed up in the following steps:

1. Division of the organization into smaller, easier to manage parts;

2. Selection of a suitable model creation method;

3. Model creation;

4. Model verification based on a prediction of historically known development;

5. Formulation of new predictions;

6. Proposal and implementation of changes in the organization using the new predictions. 
In the past, decision-making in a company at all management levels was based predominantly on previous management experience. However, in the current shifting environment, experience itself is insufficient for qualified decisions. In recent years, there has been a significant development in the theory and practice of business management, which has also been reflected in specialized literature. In the paper (Rebs et al., 2019), the authors analyse specialized literature from the field of revenue management from 2004-2017. They focused mostly on dynamic demand modelling, product range optimization and controlling.

Matsumoto and Szidarovszky (Matsumoto \& Szidarovszky, 2011) have put together a neoclassical growth model with a production function of a special shape, which corresponds to the expectation of a production delay. Other authors followed up and elaborated on this paper (Ferrara et al., 2013; Matsumoto \& Szidarovszky, 2013). Keller (Keller, 2010) analysed the possibilities of application of delay differential equations in economic dynamics and management.

The study (Aqlan et al., 2014) focuses on consolidatin of production lines by newly created simulation and optimization strategies and formulates an optimization model based on integer programming. An automatic system of production and inventory management responding to demand is analysed by (Bijulal et al., 2011). Limited production capacity and the effort to satisfy customers by a suitable combination of products are discussed in the paper by (Zhang et al., 2017).

The paper by (Shorikov \& Rassadina, 2013) deals with a methodological approach to management of the company product portfolio structure based on dynamic modelling, also accounting for feedback. The presented approach creates an optimal structure of company product lines contributing to optimization of profit and maintaining the required profit level in the long run. In (Belair \& Mackey, 1989), a dynamic model of price adjustment based on the assumption of delayed production response was created.

Effective operation of a company on the market is directly dependent on the availability of production resources. For business management, it is necessary to have the opportunity to reflect the configurations of process changes on an on-line basis in controlling processes and to introduce information flows and metrics. The publication (Aghabaghery et al., 2020) proposes a new method of process analysis utilizing event protocols as well as information about data exchange among organizational units.

Inventory management, which often has a substantial impact on the overall business performance, is considered to be one of the many functions of manufacturing and business companies. Warburton proposed a model described by delay differential equations (Warburton, 2004) for management of inventory and purchase orders, suitable for application in production management; he later extended his work and published the results in (Warburton, 2014). Csik et al. addressed the same problem earlier (Csík et al., 2010), proposing an approximate analytical solution to the problem. With regard to delay in the production process, Li created a model of price-control and management of individual commodity inventories ( $\mathrm{Li}, 2003)$.

The issue of modelling a system of storage and distribution in which the products are dispatched from a finished product warehouse directly to customers based on minimum production, storage and transport costs is described in the paper by (Bucki \& Suchánek, 2020). The aim of the paper by (Aschauer et al., 2015) is to introduce a dynamic model of relationships between logistic strategies and cargo transport. A dynamic model of damage to goods during transport from a supplier to the client is described in (Voelkel et al., 2020).

The authors (Chaudhary et al., 2018) analysed 419 of research papers concerning the issue of perishable goods storage in order to sum up its current situation and identify the directions of possible future development. (Li et al., 2017) analyse a retail supplier-client chain of perishable products in which the seller provides an option of a loan to the customers. Ways to achieve maximum profit are examined by (Feng et al., 2017) who focus on the effect of price, product freshness and inventory level on demand. 
Globalized business systems include complex supplier chains where environmental and social impacts have to be managed in accordance with various expectations of stakeholders and sustainability-related risks have to be mitigated. The paper (Rebs et al., 2019) presents an overview of dynamic models related to this topic, systemizes simulation models in terms of system thinking within a given conceptual framework and proposes a modelling procedure.

A coordination model for a Canadian pharmaceutical supply chain was processed by Weraikat et al. (2016). Supply chain relationships were also analysed by Demirel et al. (2019), who focused on the basic aspects of various inventory and production policies and formulated proposals for effective administration, management and development of supplier networks. The paper by (Cogollo-Flórez \& Correa-Espinal, 2019) strives to identify the main benefits, model types, utilized tools and research trends in the field of analytical coordination modelling and quality management integration in the supply chain. The aim of the paper by Govindan et al. (2015) was to compile an overview of recently published scientific papers in the area of management and modelling of closed reverse logistic supply chains. Quantitative models of reverse logistics for sustainable supply chains can be found in papers by Brandenburg et al. (2014) and Lozano et al. (2014).

Portfolio optimization is a fundamental question of all investors purchasing shares. In their paper, (Gruszka \& Szwabiński, 2020) model stategies of building financial portfolios in various market conditions using a set of tools from the probability theory. In their publication, (D'Albis \& AugeraudVéron, 2009) analyse the dynamic behaviour of capital growth rate using a continuous trading model. A functional analysis in portolio modelling is used by Li et al. (2015). In his publication, (Butt, 2019) Butt uses discrete probability and a similar approach is applied by Cui, Gao, and Shi. In their paper (Cui et al., 2019), the authors also account for portfolio management fees. It is worth mentioning that current literature concerning mathematical modelling in the field of finance also deals with market fraction modelling in the area of a dynamic portfolio (Cai et al., 2018). Using manufacturer's data, the authors (Midrigan \& Xu, 2014) investigate the role of financial frictions in determination of the overall productivity of factors of production and to assess the impact of the changes, they use a dynamic model of the effect of new technologies and capital gain redistribution.

The aim of the paper (Kassim et al., 2016) is to present a system dynamic model as an alternative approach to fast decision-making in determination of property rent charges. (Verani, 2018) describes a proposed model of overall balance in which entrepreneurs finance their business through a longterm agreement with a financial intermediary.

In the field of marketing, a number of economic and mathematical methods are used, including strictly formalized and heuristic methods. Selected methods are introduced in the publication by (Zvyagin, 2016). The paper by (Kozlovskyi et al., 2018) introduces the methodology of marketing strategy proposal based on a combination of classical statistical and mathematical methods and models, as well as modern information technologies, including methods of smart analytics. In marketing, correlation analysis is very important for the analysis of commodity sales. The dynamic model of correlation analysis presented in ( $\mathrm{Li}$ et al., 2020) includes selected models based on a time series database created using a commodity transaction database. The document by (Bockelie \& Belobaba, 2017) describes a new model of travellers' behaviour, simulating the choice of additional services in relation to the airline itinerary and a particular fare class.

Through viral marketing, a company may attract a lot of consumer attention with minimum financial cost. It strives to increase sales, extend its business potential and build awareness of a particular brand. The paper by (Reichstein \& Brusch, 2019) investigates the decision-making process of individuals within viral marketing using a new dynamic model. A review of publications focused on cooperative advertising was published by (Aust \& Buscher, 2014). In total, they identified 58 scientific papers using mathematical modelling.

The arrival of the Internet allowed for a fast exchange of information among consumers and a choice from a wide range of products and services, it has created new consumer demands and thus dictated the rate and type of changes. Therefore, understanding of the processes of change in the market and 
the need to adjust to them must form an integral part of the business strategy. The newest mathematical methods applied in the area of economic modelling allow us to predict the behaviour of the analysed system and account for a wide range of factors that affect the behaviour (Alharbi \& Naderpour, 2016; Fischer et al., 2015; Groesser \& Jovy, 2016). Therefore, dynamic models are now used for example as tools for support of managerial decision-making, drawing up business plans and optimization.

\subsection{Mathematical means for solving dynamic systems with delay}

Generally, dynamic models are described using ordinary differential equations, possibly integrodifferential equations and delay equations or more generally, equations with deviated arguments. All equations referred to in this paper (and many others) are special cases of the so-called functional differential equations.

The development of the theory, built systematicaly since the 20th century, has been significantly affected by the works of A.D. Myskhise (Myshkis, 1971; Kolmanovskii \& Myshkis, 1992), joint work of R. E. Bellmana with other authors (Bellman \& Danskin, 1954; Bellman \& Cooke, 1965), and (Bernfeld \& Lakshmikantham, 1974).

The available literature on solutions to systems of differential equations with delayed arguments contains many practically applicable results. An extensive and complex analysis of such equations can be found, among others, in (Bellen \& Zennaro, 2013; Kanth \& Murali, 2018) and (Kiguradze \& Půža, 2003; Kiguradze, 1997) and the literature quoted therein. The conditions of solvability, i.e. the existence and expliciteness of the problems, both general and special, are studied in detail as well as the conditions of their correctness (i.e. small solution dependencies on small changes of initial conditions and parameters necessary for the numerical solution), conditions of non-negativeness of the solution and others.

Insufficient attention is paid to a systematic description of the methods of construction of solutions to delay problems and the analysis of their applicability, in similar detail as with classic ordinary differential equations, except for the work of (Bellen \& Zennaro, 2013), using modifications of Runge-Kutta local methods of construction of solutions to delay equations, and (Gelashvili \& Kiguradze, 1995), containing a derivation of differential schemes of global approach applications within the Carathéodory theory.

Some authors currently emphasize that especially the area of differential equations with delayed arguments is suitable for a descriptin of the dynamics of the considered models, in which past situations affect the current system status (e.g. Collard et al., 2008; Doepke et al., 2015).

\subsection{Evaluation of the current status of scientific knowledge}

Company management can be viewed as a complex problem, since a company may be regarded as a system that can be imagined as a set of units that are mutually dependent, affect each other and at the same time form a cohesive whole. Same as with other systems, the parts must work in a coordinated manner for the whole system to function - in our case, to ensure successful business operation. This means that the mutual interconnections need to be managed.

Time delays are one of the basic characteristics of currently created dynamic models in business economics and management. This results from the fact that the majority of phenomena occuring in complex economic systems in the real world do not have an immediate effect but appear with a delay. Such delays may be of various types and may emerge in various forms. Current research on economic dynamics is headed to the use of ordinary differential equations with delayed arguments. This is because certain economic phenomena may not be properly described using ordinary differential equations.

The analysis of means of mathematical evaluation of dynamic models with delay shows there is a lack of a sufficiently broad systematic apparatus for the execution of numerical calculations that would at the same time not be dependent solely on specialized software applications and could be 
used everywhere where any program for numerical solution of an initial problem for ordinary differential equations and their systems is available.

Currently, the numerical calculation of solutions to differential equations and their systems is executed with the aid of now inherent computer technology. There is a very rich software allowing calculations of particular solutions of ordinary differential equations and their systems without a deviated (i.e. without a delayed or preceding or a generally deviated) argument. For ordinary differential equations and their systems with delays, such software is significantly more limited and is not equipped with algorithms allowing more complex calculations required by the practice. Moreover, this specialized yet insufficient software is usually a part of costly software packages, such as Maple or MATLAB.

\subsection{Implementation of dynamic models - model of a production, storage and sale system}

Company management must make decisions not only about the quantities to be produced and about the technology to be used, but also about the pricing of the product and how to let the consumers know about their product on the market, etc. In microeconomic theory, business decision-making is usually narrowed down to two basic problems: the decision on the output and the decision on the price.

In this paragraph, we are contemplating a non-linear mathematical model of a dynamic economic system concerned with production, storage and sale of consumer goods. The model is based on the publications by (Grigorieva \& Khailov, 2005) and (Gorski \& Lokshin, 2002) and, unlike the original model, it accounts for the fact that the changes caused by gradual consumption on the part of the customer and by damage to the goods on the part of the seller will manifest with a delay, i.e. that the system is affected by changes in the past. In the interval of $t \in[0, T]$, the model can be expressed as follows:

$$
\begin{aligned}
& x_{1}^{\prime}(t)=u(t)-n(p)\left(Y-x_{2}(t)\right) x_{1}(t)+k_{1} x_{1}\left(t-\Delta_{1}\right. \\
& x^{\prime}{ }_{2}(t)=n(p)\left(Y-x_{2}(t)\right) x_{1}(t)+k_{2} x_{2}\left(t-\Delta_{2}\right) \ldots \ldots \ldots \\
& x_{1}(0)=x_{1}^{0}, x_{2}(0)=x_{2}^{0} \ldots \ldots \ldots \ldots \ldots \ldots \ldots \ldots \ldots \ldots \ldots \ldots \ldots \ldots \ldots \ldots \ldots \ldots \ldots \ldots \ldots \ldots \ldots
\end{aligned}
$$

In the system, we consider variables $x_{1}$ - amount of goods on the market, and $x_{2}-$ customer inventory, for this reason they are non-negative. Parameters include $u$-production level, $k_{1}$ - rate of damage to goods, $k_{2}$ - rate of consumption, $p$ - selling price, $n$ - coefficient of selling rate for perishable goods $n(p)=\frac{n_{0}}{p}$ ( $n_{0}$ is a suitable constant), $Y$ - demand. Parameters $\Delta_{1}$ and $\Delta_{2}$ express the time necessary to depict the change in variables $x_{1}$ and $x_{2}$ and below will be referred to as delay. Parameters $Y, k_{1}, k_{2}$ are constants. A natural consequence of the requirement of a continuous solution $x_{i}(t)$ from the interval of $[0, T]$ to historic function $h_{i}(t)\left(t \in\left[-\Delta_{i}, 0\right]\right)$ is the specification of the initial condition of the solution $x_{i}(t)(60)$ with $x_{i}^{0}=h_{i}(0) i=\{1,2\}$.

This model can be used in planning of production or as part of models dealing with issues of cooperation or competition.

The illustrative example in the paper by (Novotná \& Škapa, 2018) is based on a real situation and uses data of a manufacturing enterprise supplying plastic cups to vending companies, i.e. companies selling and operating vending machines, in particular coffee vending machines, which is a specific service sector. The current environment means the enterprise has to deal with pressure on price reduction together with the ever increasing operating costs. It is also noticeable that competition is getting more fierce, which results in the need to pursue process optimization.

Companies operating coffee vending machines supply them at frequented spots where goods must be replenished several times a week. For this reason, it is necessary that the cup suppliers are very 
flexible in responding to their supply requirements. On the other hand, suppliers of solid parts for filling the machines have low bargaining power since there are many prospective suppliers that can replace them.

The publication by (Novotná \& Škapa, 2018) presents a model simulating a certain market situation and examines the effect of a change in historic functions and product selling price on its behaviour.

\subsection{Implementation of dynamic models - supply and demand in the poultry market}

Information and the ability to use it effectively is the greatest source of wealth in today's world. If an entrepreneur wants to be successful, they need to be aware of the environment and new trends, which may protect them in the future from sales issues, receipts drop or profit reduction.

Another example of a linear dynamic model is an equation describing market behaviour and based on the hypothesis of Walras's law that a relative change in market price over time is governed by the equation of equilibrium between demand and supply:

$$
p^{\prime}(t)=k_{1}\left(d_{1}-s_{1}+d_{2} p(t)-s_{2} p(t-\Delta)\right)
$$

The model is based on the hypothesis of Walras's law (Walras, 1984) that a relative change in market price $p(t)$ over time $t$ is governed by the equation of equilibrium between demand $D(p(t))$ and supply $S(p(t))$. A natural requirement of continuous solution $p(t)$ from interval $[0, T] \mathrm{k}$ to historic function

$$
p(t)=p_{h}(t), t \in[-\Delta, 0]
$$

where we assume function $p_{h}(t)$ to be continuous for the sake of simplification, the initial condition of solution $p(t)$ has the form

$$
p(0)=p_{h}(0) \text {, . }
$$

where $k_{1}, d_{1}, d_{2}, s_{1}, s_{2}, \Delta$ are constants $(\Delta>0)$.

If we intend to analyse the dynamics of prices, production and consumption, mostly of commodities, we can apply the Walras's law hypothesis. Then the basic dynamic formalization of the relationship is as follows:

$$
p^{\prime}=f(D(p)-S(p))
$$

while the characteristics of the model will be further analysed using linear approximation. Let us now assume that the demand responds to price changes with a certain delay. This can be mathematically formalized as follows:

$$
D(p(t))=d_{1}+d_{2} p(t), \quad d_{2}<0, S(p(t))=s_{1}+s_{2} p(t-\Delta), \quad s_{2}>0, \ldots \text { (8) }
$$

where $\Delta$ expresses the time necessary for the realization of supply change based on price development. The aim of the paper (Bobalová \& Novotná, 2015) was to analyse the behaviour of the model in terms of oscillatoricity in the event of a change in an input parameter. The application part of the publication demonstrated the construction of the model solution and presented a solution illustration in the conditions of the Czech Republic. The length of the delay corresponds to the ability of the poultry producers to adjust to market changes, which is one year. The effect of coefficient $k_{1}$, representing market sensitivity to changes in conditions was analysed.

\section{CONCLUSIONS}

The latest mathematical methods applied in the area of decision-making support in business practice allow us to work with models describing real processes with greater precision, thus allowing for predictions of behaviour of the analysed system and accounting for a wider range of factors than was previously considerable. As a result, the quality of the decision-making process will increase significantly. When specifying the structure of dynamic models from the area of business economics, we are able to describe their dynamic character with more precision by including delayed exogenous 
and endogenous variables, and if we are able to estimate the values of the respective model parameters, we can draw conclusions concerning other system behaviours, possibilities of its stabilization and monitor the effect of the individual model parameters on its solution.

\section{REFERENCES}

Aghabaghery, R., Hashemi Golpayegani, A. \& Esmaeili, L. (2020). A new method for organizational process model discovery through the analysis of workflows and data exchange networks. Social Network Analysis and Mining. 10(12), 1-10, https://doi.org/10.1007/s13278-020-0623-5

Alharbi, S., \& Naderpour M. (2016). E-Commerce Development Risk Evaluation Using MCDM Techniques. In: Lecture Notes in Business Information Processing. Plymouth; United Kingdom: Springer Verlag, 2016-05-18, s. 88. ISBN 978-331932876-8. ISSN 18651348. doi:10.1007/978-3-319-32877-5_7.

Andreeva, E. A., Kolmanovskii V. B., \& Shaikhet, L. E. (1992). Upravlenie sistemami s posledeistviem. Moskva: Nauka, Glav. red. fiziko-matematicheskoi lit-ry. ISBN 5020142360.

Aqlan, F., Lam, S. S., \& Ramakrishnan, S. (2014). An integrated simulation-optimization study for consolidating production lines in a configure-to-order production environment. International Journal of Production Economics. 148(1), 51-61. ISSN 09255273. doi:10.1016/j.ijpe.2013.11.006

Aschauer, G., Gronalt M., \& Mandl, Ch. (2015). Modelling interrelationships between logistics and transportation operations - a system dynamics approach. Management Research Review. 38(5), 505-539. ISSN 2040-8269. doi:10.1108/MRR-11-2013-0271.

Aust, G., \& Buscher, U. (2014). Cooperative advertising models in supply chain management: A review. European Journal of Operational Research. 234(1), 1-14. ISSN 03772217. doi: 10.1016/j.ejor.2013.08.010.

Belair, J., \& Mackey M. C. (1989). Consumer memory and price fluctuations in commodity markets: An integrodifferential model. Journal of Dynamics and Differential Equations. 1(3), 299-325. ISSN 1040-7294. doi:10.1007/BF01053930.

Bellen, A., \& Zennaro, M. (2013). Numerical methods for delay differential equations. 1. Oxford: OUP Oxford. ISBN 978-0-19-967137-3.

Bellman, R., \& Cooke K. L. (1965). On the computational solution of a class of functional differential equations. Journal of Mathematical Analysis and Applications. 12(3), 495-500. ISSN 0022247X. doi:10.1016/0022-247X (65)90017-X.

Bellman, R. E., \& Danskin, J. M. (1954). A Survey of the Mathematical Theory of Time-Lag, Retarded Control, and Hereditary Processes. Santa Monica, CA: RAND Corporation.

Bernfeld, S. R., \& Lakshmikantham, V. (1974). An introduction to nonlinear boundary value problems. New York: Academic Press. ISBN 01-209-3150-8.

Bijulal, D., Venkateswaran, J., \& Hemachandra, N. (2011). Service levels, system cost and stability of production-inventory control systems. International Journal of Production Research. 49(23), 7085-7105. ISSN 0020-7543. doi:10.1080/00207543.2010.538744.

Bobalová, M., \& Novotná, V. (2015). The Use of Functional Differential Equations in the Model of the Meat Market with Supply Delay. In: Procedia - Social and Behavioral Sciences. Elsevier, s. 74-79. ISSN 18770428. doi: 10.1016/j.sbspro.2015.11.406.

Bockelie, A., \& Belobaba, P. (2017). Incorporating ancillary services in airline passenger choice models. Journal of Revenue and Pricing Management. 16(6), 553-568. ISSN 1476-6930. doi:10.1057/s41272-017-0100-6.

Brandenburg, M., Govindan, K., Sarkis, J., \& Seuring, S. (2014). Quantitative models for sustainable supply chain management: Developments and directions. European Journal of Operational Research. 233(2), 299-312. ISSN 03772217. doi: 10.1016/j.ejor.2013.09.032. 
Bucki, R. \& Suchánek, P. (2020). Information Modelling of the Storage-Distribution System. Agents and Multi-agent Systems: Technologies and Applications 2019. Singapore: Springer Singapore, 2020-06-20, 2020(1), 367-376. Smart Innovation, Systems and Technologies. ISBN 978-981-13-8678-7. doi:10.1007/978-981-13-8679-4_30.

Butt, N. (2019). On Discrete Probability Approximations for Transaction Cost Problems. Asia-Pacific Financial Markets. 26(3), 365-389. ISSN 1387-2834. doi:10.1007/s10690-019-09270-8

Cai, J., Chen, X., \& Dai, M. (2018). Portfolio Selection with Capital Gains Tax, Recursive Utility, and Regime Switching. Management Science. 64(5), 2308-2324. ISSN 0025-1909. doi:10.1287/mnsc.2016.2650.

Cogollo-Flórez, J. M., \& Correa-Espinal, A. A. (2019). Analytical modeling of supply chain quality management coordination and integration: A literature review. Quality Management Journal. 26(2), 72-83. ISSN 1068-6967. doi:10.1080/10686967.2019.1580553.

Collard, F., Licandro, O., \& Puch, L. (2008). The short run dynamics of optimal growth models with delays. Annales d'Economie et Statistique. 90(1), 127-144. ISSN 0769-489X.

Connelly, B. L., Certo S. T., Ireland R. D., \& Reutzel Ch. R. (2010). Signaling Theory: A Review and Assessment. Journal of Management. 37(1), 39-67. ISSN 0149-2063. doi:10.1177/0149206310388419.

Costantino, F., Gravio G. D., Shaban, A. \& Tronci, M. (2013). Exploring the Bullwhip Effect and Inventory Stability in a Seasonal Supply Chain. International Journal of Engineering Business Management. 2013(5), 1-12. doi:10.5772/56833.

Csík, A. G., Horváth, T. L., \& Földesi, P. (2010). An Approximate Analytic Solution of the Inventory Balance Delay Differential Equation. Acta Technica Jaurinensis. 3(3), 231-256.

Cui, X., Gao, J., \& Shi, Y. (2019). Multi-period mean-variance portfolio optimization with management fees. Operational Research. 2019(1), 1-22. ISSN 1109-2858. doi:10.1007/s12351-019-00482-4

D'albis, H., \& Augeraud-Véron, E. (2009). Competitive Growth in a Life-Cycle Model: Existence and Dynamics. International Economic Review. 50(2), 459-484. ISSN 00206598. doi:10.1111/j.1468-2354.2009.00537.x

Demirel, G., Maccarthy, B. L., Ritterskamp, D., Champneys, A. R., \& Gross, T. (2019). Identifying dynamical instabilities in supply networks using generalized modeling. Journal of Operations Management. 65(2), 136-159. ISSN 0272-6963. doi:10.1002/joom.1005

Doepke, M., Hazan, M., \& Maoz, Y. D. (2015). The Baby Boom and World War II: A Macroeconomic Analysis. The Review of Economic Studies. 82(3), 1031-1073. ISSN 00346527. doi:10.1093/restud/rdv010.

Dzhalladova, I., Škapa, S., Novotná, V., \& Babynyuk, A. (2019). Design and Analysis of a Model for Detection of Information Attacks in Computer Networks. Economic Computation and Economic Cybernetics Studies and Research. 53(3), 95-112. ISSN 0424-267X. doi:10.24818/18423264/53.3.19.06

Feng, L., Chan, Y. L., \& Cárdenas-Barrón, L. E. (2017). Pricing and lot-sizing polices for perishable goods when the demand depends on selling price, displayed stocks, and expiration date. International Journal of Production Economics. 185(1), 11-20. ISSN 09255273. doi:10.1016/j.ijpe.2016.12.017

Ferrara, M., Guerrini, L., \& Bisci, G. M. (2013). Center Manifold Reduction and Perturbation Method in a Delayed Model with a Mound-Shaped Cobb-Douglas Production Function. Abstract and Applied Analysis. 2013, 1-6. ISSN 1085-3375. doi:10.1155/2013/738460

Fischer, J., Gardner, T. A., Bennett, E. M., Balvanera, P., Biggs, R., Carpenter, S. et al. (2015). Advancing sustainability through mainstreaming a social-ecological systems perspective. Current Opinion in Environmental Sustainability. 14(1), 144-149. ISSN 18773435. doi:10.1016/j.cosust.2015.06.002 
Forrester, J. W. (2013). Industrial Dynamics. 2. Cambridge: Martino Fine Books. ISBN 9781614275336.

Forrester, J. W. (1958). Industrial dynamics-a major breakthrough for decision making. Harvard Business Review. 36(4), 37-66.

Geary, S., Disney, S. M., Towill, D. R., Campuzano F., \& Mula, J. (2006). On bullwhip in supply chains-historical review, present practice and expected future impact. International Journal of Production Economics. 101(1), 23-35. doi:10.1007/978-0-85729-719-8_3

Gelashvili, Sh., \& Kiguradze, I. (1995). On multi-point boundary value problems for systems of functional differential and difference equations. Memoirs on differential equations and mathematical physics. Tbilisi: Georgian academy of sciences, (5), 1-113. ISSN 1512-0015.

Gorski, A. A., \& Lokshin B.Y. (2002). A mathematical model of goods production and sale for production supervision and planning. Fundam. Prikl. Mat. Moscow, 8(1), 39-45.

Govindan, K., Soleimani, H., \& Kannan, D. (2015). Reverse logistics and closed-loop supply chain: A comprehensive review to explore the future. European Journal of Operational Research. 240(3), 603-626. ISSN 03772217. doi: 10.1016/j.ejor. 2014.07.012

Grigorieva, E. V., \& Khailov, E. N. (2005). Attainable Set of a Nonlinear Controlled Microeconomic Model. Journal of Dynamical and Control Systems. 11(2), 157-176. ISSN 1079-2724. doi:10.1007/s10883-005-4168-8

Groesser, S. N., \& Jovy, N. (2016). Business model analysis using computational modeling: a strategy tool for exploration and decision-making. Journal of Management Control. 27(1), 61-88. ISSN 2191-4761. doi:10.1007/s00187-015-0222-1

Gruszka, J., \& Szwabiński, J. (2020). Best portfolio management strategies for synthetic and real assets. Physica A: Statistical Mechanics and its Applications. 539(1), 1-19. ISSN 03784371. doi: 10.1016/j.physa. 2019.122938

Chaudhary, V., Kulshrestha, R., \& Routroy, S. (2018). State-of-the-art literature review on inventory models for perishable products. Journal of Advances in Management Research. 15(3), 306346. ISSN 0972-7981. doi:10.1108/JAMR-09-2017-0091

Kassim, F. A. I., Nawawi, A. H., Hanipah, B. M., \& Hwa, T. K. (2016). A system dynamic model Based model for making decision to run PPP projects in Malaysia: Management (Thories and methodologies of enterprise management). In: 2016 6th International Conference on Information Communication and Management (ICICM). IEEE, 2016, s. 62-66. ISBN 978-15090-3495-6. doi:10.1109/INFOCOMAN.2016.7784216

Keller, A.A. (2010). Contribution of the delay differential equations to the complex economic macrodynamics. WTOS. 9(4), 358-371.

Kiguradze, I. (1997). An initial value problem and boundary value problems for systems of ordinary differential equations. Vol. I: Linear theory. 1. Tbilisi: Metsniereba.

Kiguradze, I., \& Půža, B. (2003). Boundary value problems for systems of linear functional differential equations. 1. Brno: Masaryk University, 104 s. ISBN 80-210-3106-9.

Kindler, E. (1980). Simulační programovací jazyky. 1. Praha: SNTL.

Kozlovskyi, S., L. et al. (2018). The marketing strategy for making optimal managerial decisions by means of smart analytics. Innovative Marketing. 14(4), 1-18. ISSN 18142427. doi:10.21511/im.14(4).2018.01

Křivý, I., \& Kindler, E. (2001). Simulace a modelování. 1. Ostrava: Ostravská univerzita. Učební texty Ostravské univerzity. ISBN 80-704-2809-0.

Li, H., Wu, Y. J., \& Chen, Y. (2020). Time is money: Dynamic-model-based time series data-mining for correlation analysis of commodity sales. Journal of Computational and Applied Mathematics. 370(1), 1-10. ISSN 03770427. doi: 10.1016/j.cam.2019.112659

Li, L., Qu, X., \& Zhang, G. (2015). An Efficient Algorithm Based on Eigenfunction Expansions for Some Optimal Timing Problems in Finance. SSRN Electronic Journal. 2015(1), 1-36. ISSN 1556-5068. doi:10.2139/ssrn.2605742 
Li, R., Chan, Y. L., Chang, Ch. T., \& Cárdenas-Barrón, L. E. (2017). Pricing and lot-sizing policies for perishable products with advance-cash-credit payments by a discounted cash-flow analysis. International Journal of Production Economics. 193(1), 578-589. ISSN 09255273. doi: 10.1016/j.ijpe.2017.08.020

Lozano, R., Carpenter, A., \& Lozano, F. J. (2014). Critical reflections on the Chemical Leasing concept. Resources, Conservation and Recycling. 86(1), 53-60. ISSN 09213449. doi: 10.1016/j.resconrec.2014.02.003.

Matsumoto, A., \& Szidarovszky, F. (2011). Delay differential neoclassical growth model. Journal of Economic Behavior \& Organization. 78(3), 272-289. ISSN 01672681. doi: 10.1016/j.jebo.2011.01.014

Matsumoto, A., \& Szidarovszky, F. (2013). Asymptotic Behavior of a Delay Differential Neoclassical Growth Model. Sustainability. 5(2), 440-455. ISSN 2071-1050. doi:10.3390/su5020440

Mc Garvey, B., \& Hannon, B. M. (2004). Dynamic modeling for business management: an introduction. New York: Springer. ISBN 03-874-0461-9.

Midrigan, V., \& Xu, D. Y. (2014). Finance and Misallocation: Evidence from Plant-Level Data. American Economic Review. 104(2), 422-458. ISSN 0002-8282. doi:10.1257/aer.104.2.422

Myshkis, A.D. (1971). Linear Differential Equations with Delayed Argument. 2. Moscow: Nauka.

Nemyckii, V.V. (1962). Topological problems of the theory of dynamical systems. Amer. Math. Soc. Transi. 5(1), 414-497.

Newton, I. (1687). Philosophice Naturalis Principia Mathematica.

Novotná, V., \& Škapa, S. (2018). Solving microeconomic model using methods of functional analysis. Economic Computation and Economic Cybernetics Studies and Research. Bucharest, 2018(1), 77-88. ISSN 0424-267X.

Rebs, T., Brandenburg, M., \& Seuring, S. (2019). System dynamics modeling for sustainable supply chain management: A literature review and systems thinking approach. Journal of Cleaner Production. 208(1), 1265-1280. ISSN 09596526. doi: 10.1016/j.jclepro.2018.10.100

Reichstein, T., \& Brusch, I. (2019). The decision-making process in viral marketing - A review and suggestions for further research. Psychology \& Marketing. 36(11), 1062-1081. ISSN 07426046. doi:10.1002/mar. 21256

Shorikov, A. F., \& Rassadina, Y. S. (2013). Dynamic optimization of the complex adaptive controlling by the structure of enterprise's product range. Economy of Region. 2013(1), 176184. ISSN 20726414. doi:10.17059/2013-2-19

Synek, M., Hoffmann, V., \& Mackenzie, I. (2013). The History and Development of Business Economics Science. Politická ekonomie. 61(4), 536-554. ISSN 00323233. doi: 10.18267/j.polek.915

Titov, N. I., \& Uspenskii, V. K. (2013). Modelirovanie sistem s zapazdyvaniem. 3. Moskva: Book on Demand. ISBN 13: 978-5458304221.

Verani, S. (2018). Aggregate consequences of dynamic credit relationships. Review of Economic Dynamics. 29(1), 44-67. ISSN 10942025. doi: 10.1016/j.red.2017.12.001

Voelkel, M. A., Sachs, A.-L., \& Thonemann, U. W. (2020). An aggregation-based approximate dynamic programming approach for the periodic review model with random yield. European Journal of Operational Research. 281(2), 286-298. ISSN 03772217. doi: 10.1016/j.ejor.2019.08.035

Warburton, R. D. H. (2004). An Analytical Investigation of the Bullwhip Effect. Production and Operations Management. 13(2), 150-160. doi:10.1111/j.1937-5956.2004.tb00151.x 